\title{
Road traffic collisions in Malawi: Trends and patterns of mortality on scene
}

\section{Francisco Schlottmann', Anna F Tyson ${ }^{1}$, Bruce A. Cairns ${ }^{1}$, Carlos Varela ${ }^{2}$, Anthony G. Charles ${ }^{1,2}$}

1.Department of Surgery, University of North Carolina, Chapel Hill, NC, USA

2.Department of Surgery, Kamuzu Central Hospital, Lilongwe, Malawi

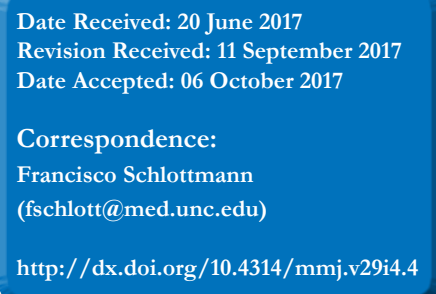

Date Received: 20 June 2017 Revision Received: 11 September 2017

Correspondence:

Francisco Schlottmann

ttp://dx.doi.org/10.4314/mmj.v

\section{Background}

Abstract

Worldwide, 90\% of injury deaths occur in low- and middle-income countries (LMIC). Road traffic collisions (RTCs) are increasingly common and result in more death and disability in the developing world than in the developed world. We aimed to examine the prehospital case fatality rate from RTCs in Malawi.

Material and Methods: A retrospective study was performed utilizing the Malawian National Road Safety Council (NRSC) registry from 2008-2012. The NRSC data were collected at the scene by police officers. Victim, vehicle, and environmental factors were used to describe the characteristics of fatal collisions. Case fatality rate was defined as the number of fatalities divided by the number of people involved in RTCs each year. Logistic regression analysis was used to determine predictors of crash scene fatality.

Results

A total of 11,467 RTCs were reported by the NRSC between 2008 and 2012. Of these, 34\% involved at least one fatality at the scene. The average age of fatalities was 32 years and $82 \%$ were male. Drivers of motor vehicles had the lowest odds of mortality following RTCs. Compared to drivers; pedestrians had the highest odds of mortality (OR 39, 95\% CI 34, 45) followed by bicyclists (OR 26, $95 \%$ CI 22, 31). The average case fatality rate was $17 \%$ / year, and showed an increased throughout the study period.

\section{Conclusions}

RTCs are a common cause of injury in Malawi. Approximately one-third of RTCs involved at least one death at the scene. Pedestrians were particularly vulnerable, exhibiting very high odds of mortality when involved in a road traffic collision. We encourage the use of these data to develop strategies in LMIC countries to protect pedestrians and other road users from RTCs.

\section{Introduction}

Globally, traumatic injury remains a significant cause of death and disability ${ }^{1,2}$. Intentional and unintentional injuries are responsible for $15 \%$ of disability-adjusted life years (DALYs) worldwide, and more people die daily from injuries than from HIV/AIDS, tuberculosis, and malaria combined ${ }^{2,3}$. Road traffic collisions (RTCs) are one of the most common preventable causes of death and disability worldwide. Low and Middle Income Countries (LMICs) account for more $90 \%$ of all road traffic deaths in the world, yet these countries have just $54 \%$ of the world's vehicles ${ }^{4}$. In addition, the mortality rate due to RTCs in LMICs is about 20.0 per 100,000 population, nearly twice as high as the rate in High Income Countries (HICs) ${ }^{4}$. Specifically in Africa, the number of road traffic injuries and deaths has been increasing over the last three decades, and the African region continues to have the highest road traffic death rates $(26.6$ per 100,000 population $)^{4}$.

Death at the scene of crash may be related with either critical and maximum injury severity or poor post-collision care. Delay in emergency services, lack of ambulance services, and shortage of pre-hospital teams certainly contribute to deaths on scene $e^{5,6}$. The larger problem facing the care of the critically injured in resource poor settings stems from a paucity of accurate data, particularly in the sub Saharan African region. Furthermore, given the reported increased incidence of road traffic fatalities in the absence of a mature trauma system, identifying the true burden of road traffic collision is imperative.
This current study uses officially collected, governmentsanctioned data to evaluate the state of RTC in Malawi while acknowledging the limitation of the data source. We believe understanding patterns of injury can help predict the need for additional services and resources, set the stage for prevention strategies, and guide health policy

\section{Methods}

This was a retrospective analysis utilizing the National Road Safety Council of Malawi (NRSCM) registry from 20082012. The NRSC is a real-time traffic police collected, crash scene database. We defined road casualty as death of any person involved in the road traffic collision (motor vehicle driver, motor vehicle passenger, motorcyclist, bicyclist, and/ or pedestrian). For each crash incident, a victim- and crashrelated characteristics associated with fatality were recorded. We used means, medians, and percentages to describe the crash- and victim-related characteristics and bivariate analysis to describe mortality-associated characteristics. Road traffic crash fatality rate was defined as the number of deaths at the scene of RTCs divided by the total number of people involved in RTCs over the study period. Similarly, the death rate from RTCs was calculated per 100,000 based on population estimates from the WHO.

Pearson's Chi-Square was used to compare categorical variables (accident severity, type of vehicle involved, location of accident, time of day, gender, type of road user, severity of injury), t-test was used to describe normally distributed continuous variables (number of people involved, age), and K-sample equality-of-means test was used for badly 
skewed continuous variables (number of deaths on scene). We performed logistic regression analysis to determine the odds of mortality based on type of road user (driver, passenger, pedestrian, bicyclist, or other). We used driver of a motor vehicle as the reference category and adjusted the regression model for age, sex, location, and time of injury. All statistical analyses were performed using Stata/IC 13.1, Stata Corp LP, College Station, TX.

The NRSCM granted us permission to use the national database, and both the University of North Carolina Institutional Review Board and the National Health Sciences Research Committee of Malawi approved this study.

\section{Results}

The NRSC reported 11,467 unique RTCs during the study period from January 2008 to December 2012. Of these, $34 \%$ resulted in at least one fatality at the scene, totaling 4,518 deaths over the five years. Motor vehicle collisions and motor vehicle versus pedestrian collisions were the most common mechanisms, accounting for $35 \%$ and $42 \%$ of all RTCs, respectively. The mean age of the victims was $32 \pm 12$ years and $88 \%$ of victims were male. Vehicular inhabitants were most commonly involved in RTCs. Pedestrians accounted for $20 \%$ of the total population, of which approximately $20 \%$ were women. Over $50 \%$ of road users involved in a collision sustained some injury, and $17 \%$ of all road users involved died at the scene [Table 1].

The highest proportions of fatalities were pedestrians, accounting for $42 \%$ of scene deaths. Although roughly equal numbers of collisions occurred in rural and urban areas, fatal RTCs were more likely to occur in rural areas. Approximately one-third of RTCs occurred at night, and nighttime collisions were also more likely to result in a fatality at the scene [Table 2].

Motor vehicular drivers had the lowest odds of mortality. Compared to drivers, pedestrians had the highest odds of mortality (OR 39, 95\% CI 34, 45). Bicyclists also had significantly high odds of mortality (OR 26, 95\% CI 22, 31) compared to drivers [Table 3].

Overall, an average of 900 people died at the scene each year from RTCs in Malawi, equating a mortality rate of $6 / 100,000$ per year. Despite the fact that the number of people involved in RTCs decreased throughout the study period, the mortality rate at the scene remained unchanged [Figure 1]. As a result, the case fatality rate increased from 14\% in 2008 to $20 \%$ in 2012 [Figure 2].
Table 1: Characteristic of Road Traffic Collisions in Malawi (2008-2012)

\begin{tabular}{|c|c|}
\hline \multirow{2}{*}{$\begin{array}{l}\text { Crash Scene Characteristics }(n=11,467) \\
\text { Accident severity }^{+}\end{array}$} & Mean ( \pm SD), Median (Range), or N $(\%)$ \\
\hline & \\
\hline Fatal & $3,904(34 \%)$ \\
\hline Severe Injury & $2,895(25 \%)$ \\
\hline Minor Injury & $3,215(28 \%)$ \\
\hline Damage to property only & $1,453(13 \%)$ \\
\hline \multicolumn{2}{|l|}{ Vehicles Involved } \\
\hline Motor Vehicle(s) & $4,051(35 \%)$ \\
\hline Motor Vehicle vs Pedestrian & $4,763(42 \%)$ \\
\hline Motor Vehicle vs Bicycle & $1,872(16 \%)$ \\
\hline Bicycle vs Pedestrian & $45(0.4 \%)$ \\
\hline Other & $735(6.4 \%)$ \\
\hline Number of People Involved & $2(1-65)$ \\
\hline \multicolumn{2}{|l|}{ Number of Deaths at the Scene } \\
\hline 0 & $7,548(66 \%)$ \\
\hline $\mathbf{1}$ & $3,561(31 \%)$ \\
\hline 2-9 & $330(2.9 \%)$ \\
\hline$\geq 10$ & $6(0.1 \%)$ \\
\hline \multicolumn{2}{|l|}{ Location of Accident } \\
\hline Rural & $5,491(48 \%)$ \\
\hline Peri-urban & $975(8.5 \%)$ \\
\hline Urban & $4,979(44 \%)$ \\
\hline Weekend & $5,394(47 \%)$ \\
\hline \multicolumn{2}{|l|}{ Time of Day } \\
\hline Daylight & $7,692(67 \%)$ \\
\hline Dawn/Dusk & $88(0.8 \%)$ \\
\hline Night & $3,687(32 \%)$ \\
\hline \multicolumn{2}{|l|}{ Victim-Related Characteristics $(n=26,486)$} \\
\hline Age (years) & $32( \pm 12)$ \\
\hline \multicolumn{2}{|l|}{ Sex } \\
\hline Male & $22,972(88 \%)$ \\
\hline Female & $3,243(12 \%)$ \\
\hline \multicolumn{2}{|l|}{ Road User } \\
\hline Driver of Motor Vehicle & $12,906(49 \%)$ \\
\hline Passenger of Motor Vehicle & $5,745(22 \%)$ \\
\hline Pedestrian & $5,278(20 \%)$ \\
\hline Bicyclist & $2,025(7.7 \%)$ \\
\hline Motorcyclist & $437(1.7 \%)$ \\
\hline Animal Driver & $31(0.1 \%)$ \\
\hline \multicolumn{2}{|l|}{ Severity of Injury } \\
\hline Killed & $4,518(17 \%)$ \\
\hline Severe & $3,861(15 \%)$ \\
\hline Minor & $6,908(26 \%)$ \\
\hline No Injury & $11,199(42 \%)$ \\
\hline
\end{tabular}

Table 2: Characteristics of Road Traffic Collisions Involving Death at the Scene

\begin{tabular}{|c|c|c|c|}
\hline Crash Scene Characteristics & Fatal & Non-Fatal & p-value \\
\hline Number & $3,904(34 \%)$ & $7,563(66 \%)$ & \\
\hline \multicolumn{4}{|l|}{ Vehicles Involved } \\
\hline Motor Vehicle(s) & $774(19 \%)$ & $3,277(81 \%)$ & \multirow{5}{*}{$<0.001$} \\
\hline Motor Vehicle vs Pedestrian & $2,091(44 \%)$ & $2,672(56 \%)$ & \\
\hline Motor Vehicle vs Bicycle & $764(41 \%)$ & $1,108(59 \%)$ & \\
\hline Bicycle vs Pedestrian & $19(42 \%)$ & $26(58 \%)$ & \\
\hline Othert & $256(35 \%)$ & $479(65 \%)$ & \\
\hline Number of People Involved & $2(1-65)$ & $2(1-54)$ & $<0.001$ \\
\hline \multicolumn{4}{|l|}{ Location of Accident $^{+}$} \\
\hline Rural & $2,480(64 \%)$ & $3,011(40 \%)$ & \multirow{3}{*}{$<0.001$} \\
\hline Peri-urban & $402(10 \%)$ & $573(7.6 \%)$ & \\
\hline Urban & $1,016(26 \%)$ & $3,963(53 \%)$ & \\
\hline Weekend $^{+}$ & $1,919(49 \%)$ & $3,475(46 \%)$ & 0.001 \\
\hline \multicolumn{4}{|l|}{ Time of Day ${ }^{+}$} \\
\hline Daylight & $2,318(59 \%)$ & $5,374(71 \%)$ & \multirow{3}{*}{$<0.001$} \\
\hline Dawn/Dusk & $32(1 \%)$ & $56(1 \%)$ & \\
\hline Night & $1,554(40 \%)$ & $2,133(28 \%)$ & \\
\hline \multicolumn{4}{|l|}{ Victim Characteristics } \\
\hline Number & $4,518(17 \%)$ & $21,968(83 \%)$ & \\
\hline Age (years) & $29( \pm 15)$ & $32( \pm 11)$ & $<0.001$ \\
\hline \multicolumn{4}{|l|}{ Sex } \\
\hline Male & $3,696(82 \%)$ & $19,276(89 \%)$ & \multirow[t]{2}{*}{$<0.001$} \\
\hline Female & $802(18 \%)$ & $2,441(11 \%)$ & \\
\hline \multicolumn{4}{|l|}{ Road User } \\
\hline Driver of Motor Vehicle & $281(2 \%)$ & $12,625(98 \%)$ & \multirow{6}{*}{$<0.001$} \\
\hline Passenger of Motor Vehicle & $1,208(21 \%)$ & $4,537(79 \%)$ & \\
\hline Pedestrian & $2,222(42 \%)$ & $3,056(58 \%)$ & \\
\hline Bicyclist & $751(37 \%)$ & $1,274(63 \%)$ & \\
\hline Motorcyclist & $49(11 \%)$ & $388(89 \%)$ & \\
\hline Animal Driver & $7(23 \%)$ & $24(77 \%)$ & \\
\hline
\end{tabular}

$\uparrow$ Includes motor vehicle or bicycle vs. animal, animal-drawn cart, or other

${ }^{+}$Column percentages describe percent of fatal and non-fatal accidents occurring at each location or time 
Table 3: Predictors of Fatality at the Scene*

\begin{tabular}{lcc}
\hline Characteristic & $\begin{array}{c}\text { Adjusted Probability of Death at the Scene } \\
\text { Probability (95\% CI) }\end{array}$ & $\begin{array}{c}\text { Odds of Fatality at the Scene } \\
\text { Odds Ratio (95\% CI) }\end{array}$ \\
\hline $\begin{array}{l}\text { Road User } \\
\text { Driver }\end{array}$ & $0.020[0.018,0.022]$ & 1 \\
Passenger & $0.166[0.156,0.177]$ & $9.83[8.54,11.31]$ \\
Pedestrian & $0.442[0.427,0.457]$ & $39.05[34.02,44.84]$ \\
Bicyclist & $0.347[0.326,0.369]$ & $26.21[22.48,30.55]$ \\
Motorcyclist & $0.097[0.074,0.128]$ & $5.31[3.83,7.37]$ \\
Animal Driver & $0.200[0.087,0.395]$ & $12.30[4.68,32.32]$ \\
\hline
\end{tabular}

*Based on the results of a logistic regression model, adjusted for age, sex, location, and time of injury. Driver of motor vehicle used as the reference

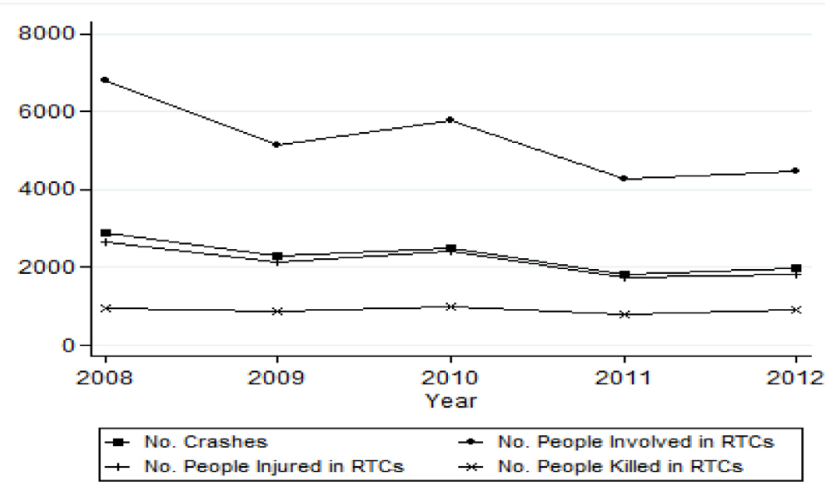

Figure 1. Trends in Road Traffic Crash Casualties and Fatalities

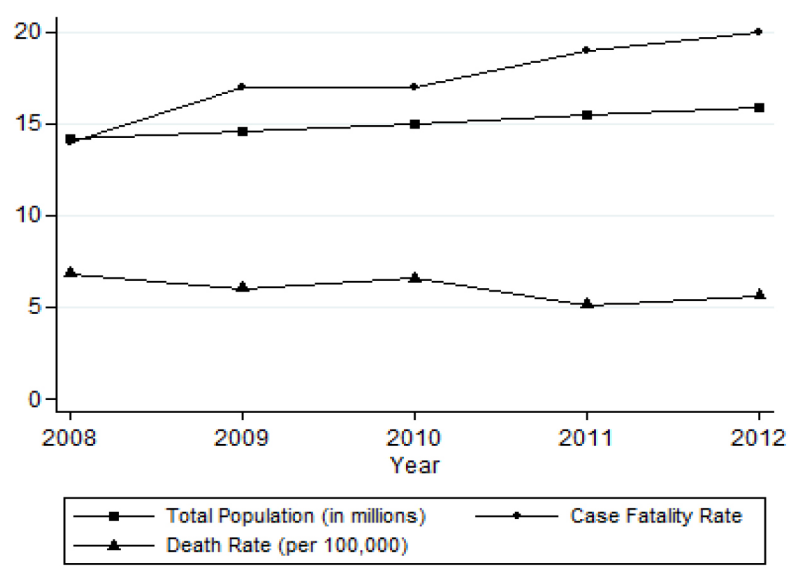

*Total Population based on World Bank estimates

Figure 2. Trends in Case Fatality Rate and Death Rate from RTCs*

\section{Discussion}

Every year almost 1.2 million lives are lost as a result of RTCs, while as many as 50 million people suffer non-fatal injuries ${ }^{4}$. Despite this overwhelming problem, relatively little attention has been paid to the management and prevention of traumatic injuries in the developing world, perhaps because road traffic injuries have long been considered to be caused by random, unpredictable events ${ }^{7}$. Africa, like the rest of the world, is witnessing a road safety crisis. RTCs account for about one-quarter of injury-related deaths in the continent overall. However, in many countries, RTCs result in more than one-third to one-half of all injury-related deaths ${ }^{8}$.

The African region remains the least motorized in the world (it only has $2 \%$ of the world's registered vehicles), but suffers the highest rates of road traffic fatalities ${ }^{9}$. Most countries in this region still lack policies for protecting vulnerable road users and promoting investment in public transportation. In addition, in most countries post-crash care is inadequate or lacking. Nigeria and South Africa have the highest fatality rates, and with five other countries (Democratic Republic of Congo, Ethiopia, Kenya, Tanzania, and Uganda) are responsible for $64 \%$ of all road deaths in the region ${ }^{10}$. Adeloye et $\mathrm{al}^{11}$ performed a meta-analysis comprising 39 studies from 15 African countries, and reported an estimated pooled rate for road traffic injury of 65.2 per 100,000 population and a death rate of 16.6 per 100,000 population. In addition, they found that road traffic injury rates increased from 40.7 per 100,000 population in the 1990 s to 92.2 per 100,000 population between 2010 and 2015 . RTCs have also important economic and disability consequences in Africa. Juillard et $\mathrm{al}^{12}$ performed a population-based survey in seven Nigerian states, and found that road traffic injuries resulted in disability for $29.1 \%$ of subjects, while $13.5 \%$ were unable to return to work. Of the disabled people, $67.6 \%$ were unable to perform activities of daily living, $16.7 \%$ consequently lost their jobs, and $88.6 \%$ had a reduction in earnings ${ }^{12}$.

In the global status report on road safety 2015, the WHO estimated fatality rate from RTCs in Malawi is 35.0 per 100,000 population ${ }^{4}$. The differences between our results and the WHO reported country statistics could be explained by the fact that only deaths at the scene of the crash were included in our analysis, rather than all deaths within 30 days of injury, as is traditionally accepted. We know from previous studies that many more victims of RTCs die in route to or at the hospital ${ }^{13}$, although we have no nationwide data on in-hospital mortality.

The causes of RTCs are multifactorial and involve the interaction of a number of pre-crash factors that include types of road users, number, type, and condition of vehicles, and lastly, the road environment ${ }^{14}$. In sub-Sahara Africa, the road transport network is inadequate compared to other regions of the world, notably in terms of quality, density, and distribution in relation to the population. The existing roads are often narrow, unpaved, and in poor condition, due to lack of regular maintenance. In addition, encroaching vegetation has further narrowed numerous rural roads, making them unsafe for both drivers and pedestrians.

In general, African countries often have very old vehicle fleets. In Ethiopia, for example, vehicles imported into the country are estimated to be on average 20 years old, and the age of the national vehicle fleet is 30 or more years. In Tanzania, the average age of vehicles is reported to be 15 years. Many of these vehicles are not road worthy ${ }^{15}$. The lack of roadworthiness of vehicles coupled with the poor road condition increases the risk of RTC. In addition, due to the high cost of fuel, transporters tend to modify their vehicles to increase carrying capacity. Such modifications may affect the structural integrity of the vehicle, thus creating enormous risks to the safety of drivers and passengers. Overloading of vehicles is a common occurrence in many parts of sub-Saharan Africa. Exceeding the allowed seating capacity in a vehicle affects vehicle handling and leaves many passengers unrestrained, placing occupants at risk for injury in a collision ${ }^{16}$. In Malawi, as in many other countries in Africa, commuters sitting on the roofs of moving vehicles or in the back of open, and crowded flat bed trucks are 
common sight.

The severity of RTCs is also likely to be much greater in Africa than elsewhere, because many more vulnerable road users are involved. This is indicative of deficiencies in both the infrastructure and road safety enforcement in Africa, which fail to separate road users and protect pedestrians from injury. The pertinent finding of this study is the stark realization of a lack of a pre-hospital system in Malawi. Changing or emphasizing road safety laws may reduce crash scene fatalities, however, those who survive the initial trauma continue to remain vulnerable to their injuries. Emergency and trauma services within the country are at best disorganized and often non-existent. Adequate postcollision care is key to reducing road fatalities on scene. A previous study has shown that even a 10 minutes reduction of the medical response time can be statistically associated with an average decrease of the probability of death by one third, both on motorways and conventional roads ${ }^{17}$. In Ghana, for example, pre-hospital emergency care services were entirely informal and extremely limited prior to the early $2000 \mathrm{~s}^{18}$. A National Ambulance Service (NAS) was established in 2004 and became fully operational in 2006. In 2014, 81\% of Ghana was covered by NAS services. This process was associated with increased mean response time, stable case holding time, and shorter vehicle engaged time, which reflects greater response ranges due to increased service uptake and improved efficiency of ambulance usage ${ }^{19}$.

Even upon arrival to a hospital, victims of RTCs face additional challenges stemming from both the lack of adequate equipment, including operating theatres and intensive care units, and the lack of trained personnel, including surgeons, anesthetists, and surgical and intensive care nursing staff ${ }^{20-22}$. Significant resources must be devoted to the care of trauma patients within the hospital system. Developing a robust pre-hospital system is expensive and will do little to improve survival if the local or regional hospitals are unable to accommodate the number of patients brought in by the emergency services. Hospitals in Malawi are often understaffed and suffer from critically limited resources.

A number of strategies and policies have contributed to dramatic decreases in RTCs in developed countries. However, these strategies may not be simply transferred to developing countries. The challenge is to determine which strategies can be adapted to the local environment, particularly in countries where road traffic deaths are increasing at an alarming rate.

Primary intervention is widely believed to be the most appropriate strategy to prevent traffic collisions. According to the 2015 WHO Global Status Report on Road Safety, effective measures include observation of road safety codes, road maintenance strategies, compulsory seatbelt use, drinkdriving laws, enforcement of speed limits in residential and commercial areas, and compulsory use of helmets for bicyclists and motorcyclists ${ }^{4}$. Several countries (including Egypt, Kenya, South Africa, Uganda and Zimbabwe) have banned the use of hand-held devices such as cellphones whilst driving. Unfortunately, the enforcement of these strategies remains weak. Considering the limited pre-hospital and hospital resources in Malawi, improving primary prevention of RTCs may be the most effective way of saving lives. Training first responders, developing an organized transportation and ambulance facilities, and setting up strategic roadside emergency trauma units in developing countries will save lives, but will require better integration and coordination between the Ministries of Transportation and Health.

There are several limitations to this study based on its retrospective database methodology. Importantly, although the NRSC data registry provide useful and important information on road traffic deaths in Malawi, police data tend to underreport injuries and death due to poor traffic police response and follow up on injured victims. In fact, since these data are limited to crash scene statistics, deaths that occur after the crash victims have been taken to the hospital are not captured in this database. In addition, there may be reporting bias due to geographical location of the crash. RTCs may be more likely to be reported if they occur on major roads and in bigger towns and cities. This would inevitably lead to the under-registration of deaths, particularly in rural areas. Countries in the African region will need to improve the data necessary for planning interventions and monitoring progress.

\section{Conclusion}

Malawi is facing a multifaceted burden of injuries due to RTCs in the most economically productive members of its society, those aged between 15 and 45 years. Approximately one-third of all RTCs involved at least one death at the scene, being the pedestrians the most vulnerable road users. By improving prevention strategies and developing a trauma system, that encompasses pre-hospital care, improved hospital surgical services, and post rehabilitation services, thousands of lives could be saved in the future.

\section{References}

1. Soreide K, Kruger A, Ellingsen C, Tjosevik K. Pediatric trauma deaths are predominated by severe head injuries during spring and summer. Scand J Trauma Resusc Emerg Med. 2009;17:3-11.

2. Norton R, Kobusingye O. Injuries. N Engl J Med. 2013;368:17231730 .

3. Meyer A. Death and Disability from Injury: A Global Challenge. J Trauma. 1998;44(1):1-12.

4. World Health Organization Global status report on road safety 2015. Available at http://www.who.int/violence_injury_prevention/road safety_status/2015/en/.Accessed 8/28/2017.

5. Farooqui JM, Chavan KD, Bangal RS, Syed MM, Thacker PJ, Alam $\mathrm{S}$, et al; Pattern of injury in fatal road traffic accidents in a rural area of western Maharashtra, India. Australas Med J 2013; 6(9):476-482.

6. Henriksson E, Oström M, Eriksson A. Preventability of vehiclerelated fatalities. Accid Anal Prev 2001; 33(4):467-475.

7. Meel B. Incidence and Patterns of Violent and/or Traumatic Deaths between 1993 and 1999 in the Transkei Region of South Africa. J Trauma. 2004;57:125-129.

8.Ncube M, Lufumpa C, Kayizzi-Mugerwa S, Murinde V. Mortality in Africa: The Share of Road Traffic Fatalities. African Development Bank;2013.

9. Peden M, Kobusingye O, Monono ME. Africa's roads: the deadliest in the world. S Afr Med J 2013; 103(4):228-229.

10. Road safety in the WHO African Region, the facts 2013. Available at:http://www.who.int/violence_injury_prevention/road_safety_ status/2013/report/factsheet_afro.pdf Accessed 8/28/2017.

11. Adeloye D, Thompson JY, Akanbi MA, Azuh D, Samuel V, Omoregbe N, et al; The burden of road traffic crashes, injuries and deaths in Africa:a systematic review and meta-analysis. Bull World Health Organ 2016; 94(7):510-521A.

12. Juillard C, Labinjo M, Kobusingye O, Hyder AA. Socioeconomic impact of road traffic injuries in West Africa: exploratory data from 
Nigeria. Inj Prev 2010; 16(6):389-392.

13. Tyson A, Varela C, Cairns B, Charles A. Hospital Mortality Following Trauma: An Analysis of a Hospital-Based Injury Surveillance Registry in sub-Saharan Africa. J Surg Educ. 2015;72(4):e66-e72.

14.Haddon W. Advances in the epidemiology of injuries as a basis for public policy. Public Health Rep. 1980;95:411-421.

15.Amibe DA. Final Draft Report on Pilot Global Fuel Economy Initiative Study in Ethiopia. Addis Ababa Institute of Technology;2012.

16.Lisinge T. Road safety versus mobility: the dilemma of managing rural transport in Africa. Geneva2011.

17. Sánchez-Mangas R1, García-Ferrrer A, de Juan A, Arroyo AM. The probability of death in road traffic accidents. How important is a quick medical response? Accid Anal Prev 2010; 42(4):1048-1056.

18. Mock CN, Tiska M, Adu-Ampofo M, Boakye G. Improvements in prehospital trauma care in an African country with no formal emergency medical services. J Trauma. 2002;53(1):90-97
19. Zakariah A, Stewart BT, Boateng E, Achena C, Tansley G, Mock C. The Birth and Growth of the National Ambulance Service in Ghana. Prehosp Disaster Med 2017; 32(1):83-93.

20.London J, Mock C, Quansah R, Abantanga F, Jurkovich G. Priorities for improving hospital-based trauma care in an African city. J Trauma. 2001;51:747-753.

21.Solagberu B, Kuranga S, Adekanye A, Ofoegbu C, Udoffa U. Preventable trauma deaths in a country without emergency medical services. Afr J Trauma. 2003.

22. Lagarde E. Road traffic injuries is an escalating burden in Africa and deserves proportionate research efforts. PLoS Med. 2007;4(6):e170. 